\title{
Multiple Electrodes for Detecting Spikes in Partial Complex Seizures
}

\author{
R. Mark Sadler and John Goodwin
}

\begin{abstract}
The contribution of various electroencephalographic electrodes in detecting spikes from patients with seizures of suspected anterior temporal origin was prospectively studied with a standard protocol. The following electrodes were studied: International Standard 10-20 positions F7-8 and A1-2, sphenoidal (SP), nasopharyngeal (NP), anterior temporal (T1-2), mandibular notch surface (MNS), and mandibular notch subdermal (MNSD). Twenty patients were recorded of whom 16 demonstrated anterior temporal spikes. There was no difference in the number of spikes detected by SP, MNS, MNSD, or T1-2 electrodes ( $p<0.05$ ); however these electrodes detected significantly more spikes than NP, F7-8, or A1-2. The SP electrode recorded spikes of highest amplitude ( $<<0.05$ ). We conclude that for patients suspected of having seizures of anterior temporal origin, (1) a substantial number of spikes will be missed if only the International Standard electrode system is employed; (2) in comparison to SP electrodes the noninvasive and easily applied MNS or T1-2 electrodes will detect almost all spikes and should be used in outpatient EEG recordings; (3) NP electrodes provide no information that cannot be obtained by more reliable and better tolerated electrodes.
\end{abstract}

\begin{abstract}
RÉSUMÉ: Utilisation d'électrodes multiples pour détecter les pointes dans l'épilepsie partielle complexe Nous avons étudié de façon prospective, en utilisant un protocole standard, la contibution de différentes électrodes électroencéphalographiques pour la détection des pointes chez des patients présentant des crises épileptiques qu'on soupçonnait être d'origine temporale antérieure. Les électrodes suivantes ont été étudiées: International Standard 10-20 en position F7-8 et Al-2, sphénoödale (SP), nasopharyngienne (NP), temporale antérieure (T1-2), de surface à l'échancrure sigmoïde de la mandibule (MNS) et sous-dermique à l'échancrure sigmoïde de la mandibule (MNSD). Nous avons fait l'enregistrement chez 20 patients, dont 16 présentaient des pointes temporales antérieures. Il n'y avait pas de différence dans le nombre de pointes détectées par les électrodes SP, MNS, MNSD ou T1-2 ( $<<0.05$ ); cependant, ces électrodes détectaient significativement plus de pointes que les électrodes NP, F7-8 ou A1-2. L'électrode SP enregistrait des pointes de plus grande amplitude $(p<0.05)$. Nous concluons que, pour les patients chez qui on soupçonne des crises épileptiques originant de la région temporale antérieure, (1) un nombre substantiel de pointes sera manqué si I'on n'utilise que le système d'électrodes International Standard; (2) par comparaison avec les électrodes SP, les électrodes MNS ou T1-2, qui sont non-invasives et d'application facile, détecteront presque toutes les pointes et devraient être utilisées pour les enregistrements électro-encéphalographiques chez tous les patients externes; (3) les électrodes NP ne fournissent pas d'information qui ne soit obenue au moyen d'électrodes plus fiables et mieux tolérées.
\end{abstract}

Can. J. Neurol. Sci. 1989; 16:326-329

In patients with partial complex seizures the detection of electroencephalographic interictal spikes assists with both diagnosis and site of ictal onset. For those patients with anterior (including mesial) temporal originating seizures the classic interictal spike is recorded from the F7-8 and ear (Al-2) electrodes 1 when the International Standard 10-20 electrode system ${ }^{2}$ is used. Additional "non-standard" electrodes have been used to augment the detection of spikes from anterior temporal lobe structures (for review see reference 3 ). However, there are few published studies that have attempted a simultaneous comparative assessment of these "non-standard" electrodes.

In this report we describe a comparative study of several electrodes used simultaneously in an attempt to define which of these is the best for detecting interictal spikes of anterior temporal lobe origin.

\section{Methods}

\section{Subjects}

Patients from one author's (RMS) outpatient epilepsy clinic were selected who fulfilled these criteria: (1) a clinical diagnosis of partial complex seizures, (2) prior standard electroencephalograms (EEGs) demonstrating spikes predominantly from F7-8, Al-2, or equipotential at F7-T3/F8-T4 and (3) agreement to participate in the study after informed consent was obtained.

From the Department of Medicine, Dalhousie University, Halifax, Nova Scotia and the Department of Diagnostic Neurophysiology, The General Hospital, St. John's, Newfoundland

Presented in part at the American Epilepsy Society Annual Meeting, Seattle, Washington, November 1986

Received November 9, 1988. Accepted in final form March 21, 1989

Reprint requests to: Dr. R. Mark Sadler, Division of Neurology, Room 2150, Ambulatory Care Center, Victoria General Hospital, Halifax, Nova Scotia, Canada B3H IY6 
All patients were sleep deprived the night prior to the study recording session. To ensure sleep, secobarbital $100 \mathrm{mg}$ was orally administered upon arrival in the EEG laboratory. There were no adjustments of anti-epileptic medications.

Patient data was obtained from the clinic charts.

\section{EEG Recording Parameters}

Silver-silver chloride surface cup electrodes were applied to the following International 10-20 positions: ${ }^{2}$ F3-4, F7-8, T3-4, A 1-2, CZ and PZ. Identical electrodes were applied bilaterally to the "anterior temporal" (T1-2) positions (one-third of the distance from the external auditory meatus to the external canthus of the eye and up one centimeter $)^{4}$ and over the mandibular notch surface (MNS) located $2.5 \mathrm{~cm}$ anterior to the tragus of the ear and immediately inferior to the zygoma. Platinum alloy subdermal needle EEG electrodes ${ }^{5}$ (mandibular notch subdermal or MNSD) were inserted immediately adjacent to the MNS electrodes. Sphenoidal (SP) electrodes (silver-silver chloride wire insulated but bared at the tip) were inserted adjacent to MNS and MNSD electrodes using standard techniques. ${ }^{6}$ Nasopharyngeal (NP) silver-silver chloride ball electrodes were used in all but two patients (who could not tolerate insertion).

All electrodes were referred to $\mathrm{PZ}$ except $\mathrm{A} 1$ and $\mathrm{A} 2$ which were linked (A1-A2) and used as a monitor of electrocardiogram artefact; T3-4 were linked to $\mathrm{CZ}$ to identify sleep potentials.

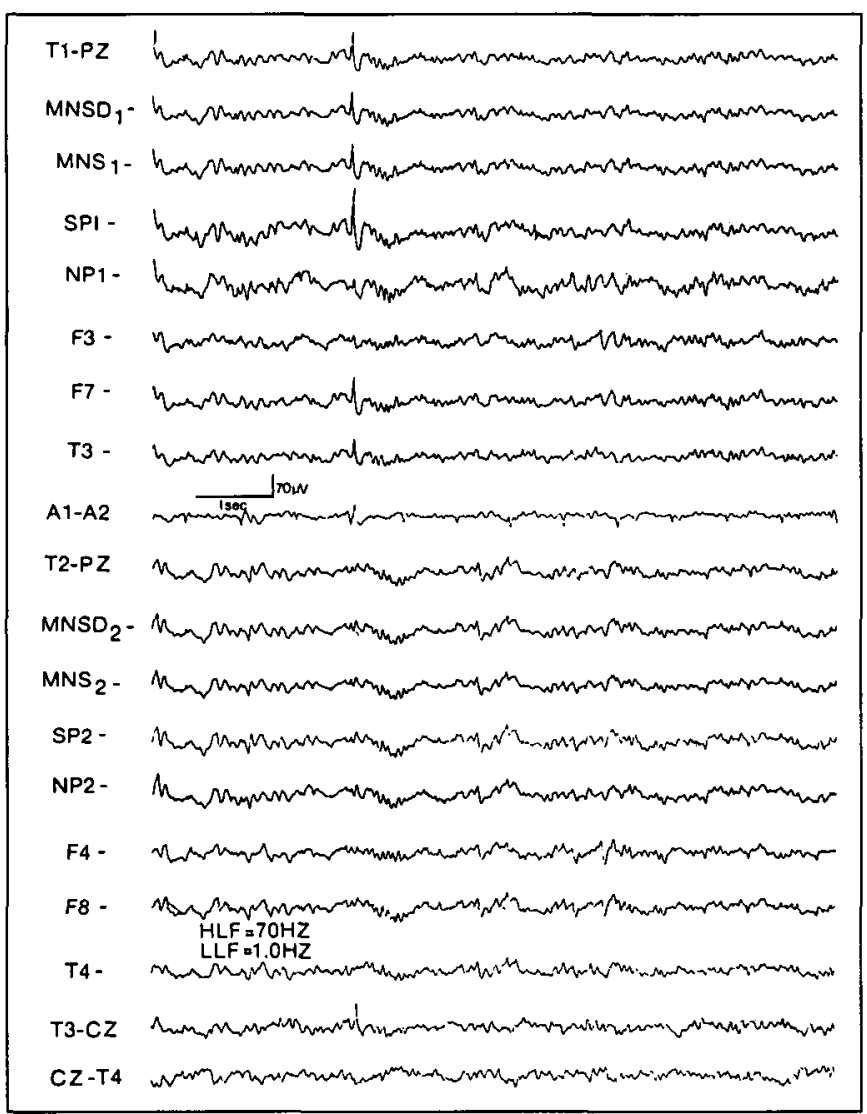

Figure I - Left temporal spike in one study montage: spike detection by all left side non-standard electrodes, AI, F7 and T3; maximum amplitude at SPI. See text for abbreviations; all electrodes referred to $P Z$ unless otherwise indicated.
All recordings were performed with a Grass Model 819 Channel electroencephalograph.

\section{EEG Data Collection}

The EEG technologist constructed four montages using the channel derivations described above; all montages contained the same channel derivations but in a different order. The electroencephalographer was blind to the channel derivation sequences in each montage until the study was terminated.

The technologist selected one montage per patient and one montage was used throughout one recording session; each patient had a single recording.

EEGs were visually inspected and spikes identified using Gloor's criteria ${ }^{7}$ as closely as possible. Whenever a spike was observed in any channel, waveforms occurring simultaneously in other channels were inspected for spike characteristics. Only those channels with spike morphology were counted as "detections"; other simultaneous waveforms (e.g. sharply contoured theta waves) were counted as "non-detections". Each spike's amplitude was determined by measuring (with calipers) the vertical distance between the peak pen deflection and the lowest trough on either the ascending or descending phase of the spike.

After all spikes were assessed channel derivation codes were broken. Spikes expressing maximal amplitude at F3-4 and T3-4 were excluded. Spikes in the A1-A2 channel were not measured for amplitude but were counted in the detection data. Small sharp spikes (benign epileptiform transients of sleep) were excluded 8

Spikes from each electrode were analyzed according to detection, amplitude (except A1, A2), and concordance of detection with other electrodes. Statistical testing was performed using the Tukey honestly significant difference (hsd) procedure for multiple comparisons, ${ }^{9}$ at $95 \%$ confidence limits.

Figure 1 illustrates one study montage and a typical spike detected by multiple electrodes.

\section{Patients}

Twenty patients were studied; four had no spikes and were excluded from further analysis. The mean age was 32.1 years (range 17-60). All had normal neurological examinations, normal intelligence (with the exception of 1 patient with mild mental subnormality), and normal contrast enhanced computed tomographic brain scans.

The mean recording time was 88 minutes (range 85-95) with awake and sleep recordings obtained in all patients.

\section{Spike Detections}

One hundred and ninety-two spike "events" were identified with a mean ( \pm standard deviation) of $12 \pm 8.5$ per patient.

Spike detections by each electrode are shown in Table 1. There was no statistically significant difference in the number of detections amongst the SP, MNS, MNSD and T1-2 electrodes. However, each of these electrodes detected more spikes ( $\mathrm{p}<0.05$ ) than the F7-8, NP, or Al-2 electrodes (allowing for the two patients who did not have NP electrodes inserted). There was no difference in detections amongst F7-8, Al-2 and NP electrodes.

There were four patients (with 16,11,1 and I spike "events", respectively) who would not have had any detections 
Table 1: Spike Detections and Amplitudes by Electrode

\begin{tabular}{lcccc}
\hline \hline Electrode & $\begin{array}{c}\text { Detections } \\
\text { (Total = 192) } \\
\text { \% of Total }\end{array}$ & $\begin{array}{c}\text { Mean } \\
\text { Qmplitude } \\
\text { (Microvolts) }\end{array}$ & $\begin{array}{c}\text { Standard } \\
\text { Deviation of } \\
\text { Amplitude }\end{array}$ \\
\hline SP & 187 & $97.3^{\mathrm{a}}$ & $140^{\mathrm{a}}$ & 42 \\
MNS & 178 & $92.7^{\mathrm{a}}$ & $105^{\mathrm{b}}$ & 30 \\
MNSD & 178 & $92.7^{\mathrm{a}}$ & $105^{\mathrm{b}}$ & 31 \\
T1-2 & 166 & $86.4^{\mathrm{a}}$ & $107^{\mathrm{b}}$ & 34 \\
F7-8 & 111 & $57.8^{\mathrm{b}}$ & $119^{\mathrm{b}}$ & 38 \\
A1-2c & 107 & $55.7^{\mathrm{b}}$ & - & - \\
NPd & 100 & $62.9^{\mathrm{b}}$ & $110^{\mathrm{b}}$ & 33 \\
\hline
\end{tabular}

a,b Values in column with the same superscript not significantly different $(p<0.05)$

c Spike amplitude of A1, A2 spikes not measured

d Two patients with a total of 33 spikes did not have NP electrodes; percentage calculated from a total of 159 spikes in those patients with NP electrodes

if only F7-8 and Al-2 were used and all patients would have had spikes detected if any one of the non-standard electrodes had been used.

\section{Spike Amplitudes}

The mean ( \pm standard deviation) of spike amplitude at each electrode position is shown in Table 1 . There was no statistically significant difference in mean amplitude at any of the sites except for the SP electrode which demonstrated spikes of a higher mean amplitude than any other electrode $(p<0.05)$

\section{Concordance of Detection}

Table 1 describes the number of detections by each electrode but seventeen different combinations of detections were observed amongst the electrodes. For example, one spike event might be detected only by SP and the mandibular notch electrodes but on other occasions more widespread involvement could occur (Figure 1).

Virtually all (92-97\%) NP spikes were simultaneously detected by the other non-standard electrodes but only 61-69\% of SP, MNS, MNSD, or T1-2 spikes were concordant with NP spikes.

The non-standard electrodes (except NP) simultaneously detected $97-98 \%$ of $\mathrm{F} 7-8$ or Al-2 spikes whereas the converse was true in $58-65 \%$ of instances.

\section{Discussion}

When the International Standard 10-20 Electrode System ${ }^{2}$ is used the interictal spikes in patients with anterior temporal lobe originating seizures are typically recorded from the F7-8 and A1-2 electrodes. ${ }^{1}$ However, F7-8 is in closer proximity to the inferior frontal lobe than the temporal lobe ${ }^{10}$ and therefore may not be optimally positioned for detecting anterior temporal discharges. A number of non-standard electrodes have been described to augment anterior temporal detections; ${ }^{3}$ sphenoidal,"l nasopharyngeal, 12-14 "anterior temporal" (T I-2), ${ }^{4}$ and more recently "mini-sphenoidal",5 and zygomals electrodes.

Despite abundant documentation over many years of the non-standard electrodes' abilities to detect spikes ${ }^{3}$ there have been few attempts to critically evaluate the performance of any one of these electrodes against others. Eleven studies in the literature have simultaneously evaluated at least two of the nonstandard electrodes; four of these are presented in abstract form ${ }^{17-20}$ and a critical appraisal is not possible; the seven complete publications $5,15,16,21-24$ are summarized in Table 2 .

Our study is the first to assess simultaneously SP, NP, MNS, MNSD and T1-2 electrodes with a standard protocol. Despite methodological differences, our findings generally agree with the conclusions of previous studies (Table 2).

In the present study the SP spikes had a significantly greater mean amplitude than the spikes detected by all other electrodes. Although the SP electrodes detected more spikes than either of the MNS, MNSD, or T1-2 electrodes, this difference was not statistically significant. The performance of the MNS, MNSD and T1-2 electrodes as measured by both amplitude and detection was statistically indistinguishable and each of these electrodes detected more spikes than NP, F7-8, or A1-2 electrodes.

The concordance data suggests that the neural generators for spikes detected by SP, MNS, MNSD and T1-2 electrodes are similar; therefore only one of these electrodes need be used in the individual patient if one wishes to determine only the presence of anterior temporal originating spikes. However, by using multiple electrodes a more comprehensive evaluation of the electrical field can be obtained. ${ }^{22,23}$ Using any of SP, MNS,

Table 2: Comparative Studies Using a Minimum of Two Non-Standard Electrodes in Patients with Partial Complex Seizures

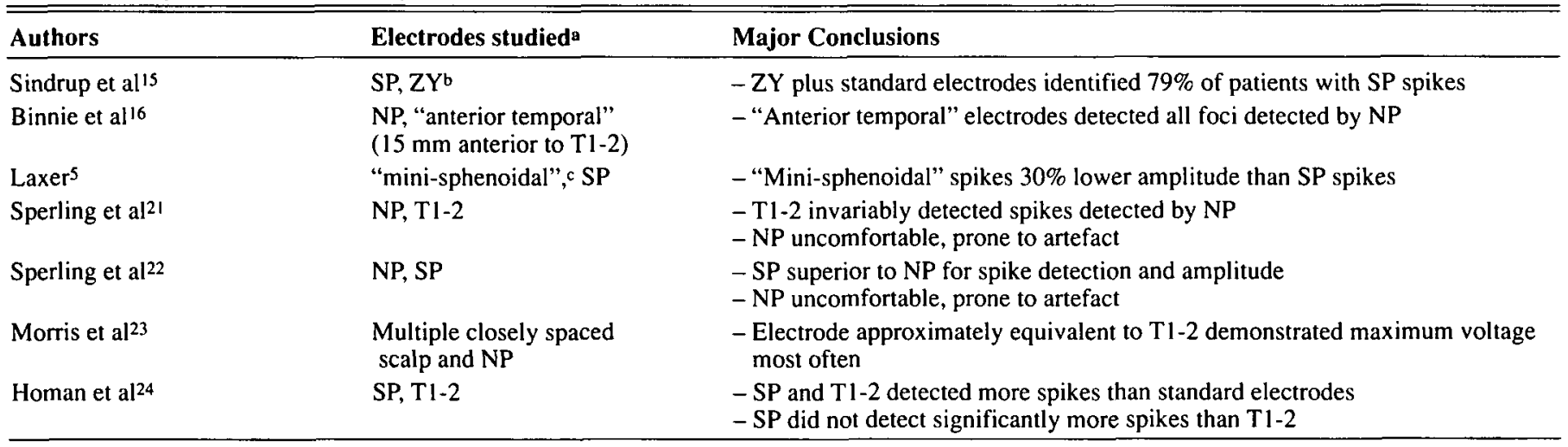

\footnotetext{
a In addition to standard scalp electrodes

b Probably equivalent to MNS electrodes in present study

c Equivalent to MNSD electrodes in present study
} 
MNSD, or T1-2 electrodes will substantially increase the likelihood of detecting anterior temporal spikes beyond that which can be achieved with the International Standard 10-20 system ${ }^{2}$ alone since the F7-8 and Al-2 electrodes detected only $58 \%$ and $56 \%$, respectively, of all spikes.

The advantages of MNS and T1-2 electrodes compared to SP electrodes for out-patient EEG recording are the lack of patient discomfort and a physician is not required for placement.

The NP electrodes detected significantly fewer spikes than SP, MNS, MNSD, or T1-2 electrodes. Further, when a NP spike was seen it was nearly always detected by one of the other nonstandard electrodes. Therefore we have found, as have other authors, ${ }^{21,22}$ that NP electrodes provide no information that cannot be obtained with more reliable and comfortable electrodes.

\section{ACKNOWLEDGEMENTS}

We thank Dr. David Bryant for statistical help and both Mrs. Linda E. Lush and Mrs. Debbie E. Clarke for secretarial assistance.

\section{REFERENCES}

1. Niedermeyer E, Lopes da Silva F. Electroencephalography: basic principles, clinical applications and related fields. Second edition, Baltimore-Munich: Urban and Schwarzenberg 1987; 465.

2. Jasper HH. The ten-twenty electrode system of the International Federation. Electroenceph Clin Neurophysiol 1958; 10: 371375.

3. Morris HH, Luders H. Electrodes. In: Gotman J, Ives JR, Gloor P, eds. Long-term Monitoring in Epilepsy. Electroenceph Clin Neurophysiol 1985; 37 (Suppl): 3-26.

4. Silverman D. The anterior temporal electrode and the ten-twenty system. Electroenceph Clin Neurophysiol 1960; 12: 735-737.

5. Laxer KD. Minisphenoidal electrodes in the investigation of seizures. Electroenceph Clin Neurophysiol 1984; 58: 127-129.

6. Ives JR, Gloor P. New sphenoidal electrode assembly to permit long-term monitoring of the patient's ictal or interictal EEG. Electroenceph Clin Neurophysiol 1977; 42: 575-580.

7. Gloor P. The EEG and differential diagnosis of epilepsy. In: Van Duyn H, Donker DNJ, Van Huffglen AC, eds. Current Concepts in Clinical Neurophysiology. The Hague: NV Drukker Trio 1977: 9-21.

8. Klass DW. Electroencephalographic manifestations of complex partial seizures. In: Penry JK, Daly DD, eds. Advances in Neurology, Vol. 11. New York: Raven Press 1975; 2: 113-140.
9. Steel RGD, Torrie JH. Principles and procedures of statistics. New York: McGraw-Hill 1971; 2.

10. Homan RW, Herman J, Purdy P. Cerebral location of international 10-20 system electrode placement. Electroenceph Clin Neurophysiol 1987; 66: 376-382.

11. Jones DP. Recording of the basal electroencephalograph with sphenoidal needle electrodes. Electroenceph Clin Neurophysiol 1951; 3: 100.

12. Grinker RR. A method for studying and influencing corticohypothalamic relations. Science 1938; 87: 73-74.

13. Gastaut $H$. Presentation d'une electrode pharyngee bipolaire. Rev Neurol 1948; 80: 623-624.

14. MacLean PD. A new nasopharyngeal lead. Electroenceph Clin Neurophysiol 1949; 1: 110-112.

15. Sindrup E, Thygesen N, Kristensen O, et al. Zygomatic electrodes: their use and value in complex partial epilepsy. $\ln$ : Dam $\mathrm{M}$, Gram L, Penry JK, eds. Advances in Epileptology: XII Epilepsy International Symposium. New York: Raven Press 1981; 313318.

16. Binnie CD, Dekker E, Smit A, et al. Practical considerations in the positioning of EEG electrodes. Electroenceph Clin Neurophysiol 1982; 53: 453-458.

17. Jones M, Rawat S, Reed J, et al. Comparison of TI-2 electrodes vs. sphenoidals for evaluation of complex partial seizures. Electroenceph Clin Neurophysiol 1984; 58: $31 \mathrm{P}$ (Abstract).

18. Marcus RW, So E, King DW, et al. Comparison of sphenoidal, nasopharyngeal, and surface electrodes in evaluating patients with partial complex seizures. Epilepsia 1984; 25: 652 (Abstract).

19. Buchhalter J, Schomer SS, Schacter S, et al. A comparative study on the sensitivity of the mini and standard sphenoidal electrode. Epilepsia 1987; 28: 611-612 (Abstract).

20. Ito BM, Sato $S$, Devinsky $O$, et al. Sphenoidal versus true anterior temporal electrodes for the detection of epileptiform discharges. Neurology 1988; 38 (Suppl 1): 234 (Abstract).

21. Sperling MR, Engel $J$ Jr. EEG from the temporal lobes: a comparison of ear, anterior temporal, and nasopharyngeal electrodes. Ann Neurol 1985; 17: 510-513.

22. Sperling MR, Mendius JR, Engel J Jr. Mesial temporal spikes: a simultaneous comparison of sphenoidal, nasopharyngeal, and ear electrodes. Epilepsia 1986; 27: 81-86.

23. Morris HH, Luders H, Lesser RP, et al. The value of closely spaced scalp electrodes in the localization of epileptiform foci: a study of 26 patients with complex partial seizures. Electroenceph Clin Neurophysiol 1986; 63: 107-111.

24. Homan RW, Jones MC, Rawat S. Anterior temporal electrodes in complex partial seizures. Electroenceph Clin Neurophysiol 1988; 70: 105-109. 